\title{
Intra-operative and Immediate Post-operative Complications in a High Volume Cataract Surgery Center
}

\author{
Muhammad Ali Haider ${ }^{1}$, Uzma Sattar ${ }^{2}$, Muhammad Amjad ${ }^{3}$ \\ Department of Ophthalmology, ${ }^{1}$ Al-Ehsan Eye Hospital, ${ }^{2}$ Rahbar Medical \& Dental College Lahore, ${ }^{3}$ Huddersfield \\ Royal Infirmary, UK
}

\begin{abstract}
Purpose: To find out the frequency of complications in a high volume phacoemulsification set up at a tertiary care eye hospital in Lahore.

Study Design: Quasi experimental study.

Place and Duration of Study: Al-Ehsan Eye Hospital, Lahore, from July 2017 to June 2019.

Methods: Surgical outcomes of 6,902 patients who had undergone phacoemulsification were included. Patients were excluded if they had ocular infections, lid margin diseases, adnexal diseases, those requiring a secondary anterior chamber surgery and those unfit for the procedure due to medical grounds. Every patient underwent a detailed history and complete clinical examination. All patients underwent standard phacoemulsification technique with intraocular lens implantation in most of the cases. Complications encountered during high volume cataract surgery were recorded and their percentages were calculated.
\end{abstract}

Results: A total of 6.902 patients underwent cataract surgery with $2.66 \%$ intra-operative and $6.94 \%$ immediate post-operative complications. The most common intra-operative complication was posterior capsular rupture $(1.15 \%)$. In patients with capsular rupture the intra ocular lens was implanted within the sulcus in 61 cases $(0.88 \%)$ while in 12 cases $(0.17 \%)$ anterior chamber lens was implanted because of lack of capsular support. During the surgery intra ocular lens could not be implanted in 7 cases $(0.10 \%)$ and they were left aphakic. The commonest immediate post-operative adverse outcome was corneal edema with striate keratopathy and decements folds in 197 cases (2.85\%).

Conclusion: High volume cataract surgery using appropriate techniques and sterilization does not compromise the quality of outcomes.

Key Words: Cataract, Phacoemulsification, Vitreous loss.

How to Cite this Article: Haider MA, Sattar U, Amjad M. Intra-operative and Immediate Post-operative Complications in High Volume Cataract Surgery Center. Pak J Ophthalmol. 2020; 36 (4): 371-375.

Doi: https://doi.org/10.36351/pjo.v36i4.1059

Correspondence: Muhammad Ali Haider

Department of Ophthalmology

Al-Ehsan Eye Hospital, Lahore

Email: alihaider_189@yahoo.com

Received: April 28, 2020

Accepted: July 21, 2020

\section{INTRODUCTION}

There are multiple etiologies that can cause formation of cataracts. ${ }^{1,2}$ Numerous medications were investigated to treat cataract; including sorbitollowering agents, aspirin, glutathione-raising agents and antioxidant vitamins $\mathrm{C}$ and $\mathrm{E}^{3}$. The definite treatment of cataracts still remains removal through surgery and implantation of an intra-ocular lens. ${ }^{4,5,6}$ With an advancing age and early presentation, the 
disease burden has increased in recent years and despite the advancements in surgical techniques and equipment it poses a significant challenge to the health services. $^{7,8,9}$ This is especially a problem in the developing world where lack of disease awareness, lack of education, under developed health services, financial constraints all add up and compound the problems. High volume cataract surgery is now a common practice in most parts of the developing world. $^{10,11}$

High volume phacoemulsification is a routine at Al-Ehsan eye hospital, Lahore. A large proportion of patients presenting at the hospital are diagnosed with cataracts and undergo phacoemulsification. In the light of this practice, a study was conducted at the hospital where cases operated by a high volume surgeon were analyzed for per-operative and post-operative complications.

\section{METHODS}

Al-Ehsan Eye Hospital, Lahore is a tertiary care eye hospital with a large outpatient and surgical volume. The study was conducted during the period from July 2017 to June 2019. The patients were operated by a single qualified surgeon who operated more than eighty (80) cases per week. Ethical approval was sought and consent was taken from every patient before surgery. This study included all patients between 20 and 90 years, whose best corrected visual acuity did not improve by refraction. Other indications for cataract surgery included diagnosis and treatment of any associated underlying retinal pathology, performing relevant posterior segment investigations such as OCT, FFA, Visual fields etc. Patients were excluded from study if they had underlying ocular infections, lid margin diseases, associated adnexal diseases, those requiring a secondary anterior chamber surgery and those deemed unfit to undergo the procedure on medical grounds.

All patients were recruited from the outpatient department at the hospital. Patients underwent a standard protocol from advice of procedure to surgery. Every patient on presentation underwent a detailed examination that included a brief history, refraction, anterior segment examination and IOP measurement followed by detailed fundus examination. All patients underwent baseline blood tests, viral serology with ELISA and biometry with IOL Master for IOL power calculations. All patients were prepped with disposable surgical caps and gowns, vitals were recorded, eyes were marked, pupils were dilated using the $2.5 \%$ Phenylephrine and 1\% Mydriacyl eye drops and patients were then taken to the surgical operating room for surgery.

The surgery was performed by the surgeon using two fully equipped eye surgical stations. Each stationed was manned by an assisting nurse for the surgical trolley and two supporting staff members who assisted in shifting of the patients, providing consumables to the assisting nurse and the surgical team. Each station was equipped with an operating microscope, Phacoemulsification machine, operating table and surgeon chair.

A strict sterilization protocol was followed for the instrument sterilization. The eye to be operated was cleaned with Povidone Iodine solution before the surgery by the assisting nurse. Patients with negative serology for hepatitis B and C viruses were operated first followed by those with positive blood tests for hepatitis $\mathrm{B}$ and $\mathrm{C}$ viruses. The surgeon switched in between the two operating stations where the prepared patients were ready for surgery. All patients underwent the standard phacoemulsification technique and at the end of each surgery, subconjunctival injections of dexamethasone and gentamycin were given to the patients. Any per-operative event was documented after the surgery.

All eyes were covered with an eye pad and all patients prescribed steroid and antibiotics eye drops. The patients were instructed to remove the eye pads four hours after surgery and start the drops at two hourly intervals. The patients were examined on the next day in outpatient department by the operating surgeon who documented any post-operative complications in the cases.

\section{RESULTS}

The per-operative complications encountered during the high volume surgery varied in spectrum. The most common intra-operative complication recorded was posterior capsular rupture in 80 cases $(1.15 \%)$. Vitreous loss with posterior capsular rupture requiring anterior vitrectomy was encountered in 63 cases $(0.91 \%)$ while 17 cases $(0.24 \%)$ had no vitreous prolapse. In patients with capsular rupture the intra ocular lens was implanted within the sulcus in 61 cases $(0.88 \%)$ while in 12 cases $(0.17 \%)$ anterior chamber lens was implanted. Lens matter drop into the posterior 
vitreous cavity was encountered in 4 cases $(0.05 \%)$ that had capsular rupture. Two cases $(0.002 \%)$ had nucleus drop during the surgical procedure. During the surgery intra ocular lens could not be implanted in 7 cases $(0.10 \%)$ and they were left aphakic. While preforming phacoemulsification Iris was damaged in 9 cases $(0.13 \%)$. Per operative surgical hyphema secondary to mechanical trauma was encountered in 5 cases $(0.05 \%)$. In 4 cases $(0.05 \%)$ the lens haptics were damaged that required replacement (table1)

Table 1: Frequency of Per-operative Complications during High Volume Cataract Surgery (Percentage).

\begin{tabular}{lcc}
\hline \multicolumn{2}{c}{ Intra-Operative Complications } \\
Complication & $\begin{array}{c}\text { No of } \\
\text { Patients }\end{array}$ & Percentage \\
\hline $\begin{array}{l}\text { Posterior capsular rupture with } \\
\text { vitreous loss }\end{array}$ & 63 & $0.91 \%$ \\
$\begin{array}{l}\text { Posterior capsular rupture with no } \\
\text { vitreous loss }\end{array}$ & 17 & $0.24 \%$ \\
IOL implant in sulcus & 61 & $0.88 \%$ \\
AC IOL implant & 12 & $0.17 \%$ \\
Posterior capsular rupture with lens & 4 & $0.05 \%$ \\
matter drop in vitreous & 2 & $0.002 \%$ \\
Nucleus Drop & 7 & $0.10 \%$ \\
Aphakia & 9 & $0.13 \%$ \\
Iris Chop & 5 & $0.07 \%$ \\
Surgical Hyphema & 4 & $0.05 \%$ \\
Broken Haptic &
\end{tabular}

Post-operatively the most common adverse outcome was corneal edema with striate keratopathy and decements folds in 197 cases (2.85\%). This adverse outcome was associated with hard cataracts that required excessive chamber manipulation during chopping and phacoemulsification. The most serious complication was intense anterior chamber activity with residual hypopyon in 3 cases $(0.04 \%)$ on the immediate post-operative day. These patients were promptly treated on the treatment guidelines of postoperative endophthalmitis (table 2).

Table 2: Immediate Post-operative Complications in High Volume Cataract Surgery.

\begin{tabular}{lcc}
\hline Complication & No of Patients & Percentage \\
\hline $\begin{array}{l}\text { Corneal edema + striate } \\
\text { keratopathy and DM folds }\end{array}$ & 197 & $2.85 \%$ \\
$\begin{array}{l}\text { Anteriorchamber reaction } \\
\text { (> + Cells) }\end{array}$ & 167 & $2.41 \%$ \\
Corneal edema & 83 & $1.20 \%$ \\
$\begin{array}{l}\text { Displaced IOL requiring } \\
\text { repositioning }\end{array}$ & 11 & $0.15 \%$ \\
Wound leak + shallow & 6 & $0.08 \%$
\end{tabular}

anterior chamber

$\begin{array}{lll}\text { Residual cortex/lens matter } & 7 & 0.10 \%\end{array}$

$\begin{array}{lll}\text { Hyphema } & 5 & 0.07 \%\end{array}$

Hypopyon $\quad 3 \quad 0.04 \%$

\section{DISCUSSION}

Cataract is the commonest cause of decreased vision in older age in developing countries like Pakistan. ${ }^{4}$ In developing countries the increased number of patients with cataract is due to lack of education, lack of disease awareness, under-developed health facilities and financial constrain. In such circumstances, high volume cataract surgery is now a common practice in most parts of the developing world.

The same high volume surgical approach was adopted in our surgical setting where we focused on different intra-operative and post-operative complications encountered during high volume cataract surgery operated by a single surgeon. ${ }^{12}$ The average surgery time was approximately 3 minutes and approximately $8-10$ surgeries were performed in a single hour. Venkatesh et al. documented $1.9 \%$ intraoperative and $12.6 \%$ immediate postoperative complications of three high volume surgeons in a community based hospital. Their average surgical time was 3.75 minutes per case. ${ }^{13}$

In a population based analysis in Ontario, Canada the association of annual surgeon volume of cataract procedures with their risk of post-operative adverse events was documented. There were 284797 cataract surgeries in patients older than 20 years performed at 70 hospitals or eye surgery centers. Fewer than 1 in 200 patients experienced an adverse event (range $0.33 \%-0.41 \%$ ). Surgeons performing 50 to 250 cataract surgeries per year had an adverse event rate of $0.8 \%$. Surgeons performing 251 to 500 cataract surgeries per year had an adverse event rate of $0.4 \%$. Surgeons performing 501 to 1000 cataract surgeries per year had an adverse event rate of $0.2 \%$ and surgeons performing more than 1000 cataract surgeries per year had an adverse event rate of $0.1 \% .^{14}$

In our study over a course of two years the intraoperative and immediate post-operative complications rate in surgeries performed by a single surgeon was $2.78 \%$ and $6.94 \%$ respectively. The most common problem faced after the cataract extraction was corneal edema with striate keratopathy and folds in decements membrane in approximately $1.39 \%$. It occurred due to excessive chamber manipulation during chopping of 
the lens. This settled approximately after 2 weeks by using intensive steroid therapy every 2 hours in the first week followed by four times a day in the $2^{\text {nd }}$ week. The commonest intra-operative complication recorded was posterior capsular rupture in total of 80 cases $(1.15 \%)$. The capsular rupture was dealt most commonly with lens implanted in sulcus $(0.88 \%) .^{15}$

The modified sterilization and asepsis protocol adopted to facilitate high-volume cataract surgery in our clinical setting appeared to be safe and effective in preventing postsurgical endophthalmitis with a very low frequency comparable to other studies. ${ }^{16}$ In a study conducted at Aravind eye hospital on more than 42,000 consecutive cases of high volume cataract surgery, the incidence of endophthalmitis was $0.09 \%$ after using a standardized sterilization and prophylaxis protocol. ${ }^{17}$

Our study shows that by using appropriate sterilization and asepsis protocol, in the hands of an experienced surgeon, high volume cataract surgery does not compromise the surgical outcome with a very low rate of complications that are comparable to other studies. $^{18}$ High volume cataract surgeries are affordable, cost effective and if made a standard practice can help in tackling high levels of preventable blindness in the developing countries. ${ }^{19,20}$ Thus, more data should be collected to develop standard protocols for high volume cataract surgeries.

\section{CONCLUSION}

High volume cataract surgery using appropriate sterilization techniques does not compromise quality of outcomes.

\section{Ethical Approval}

The study was approved by the Institutional review board/Ethical review board.

\section{Conflict of Interest}

Authors declared no conflict of interest.

\section{REFERENCES}

1. Lundström M, Barry P, Henry Y, Rosen P, Stenevi U. Visual outcome of cataract surgery; study from the European Registry of Quality Outcomes for Cataract and Refractive Surgery. J Cataract Refract Surg. 2013; 39 (5): 673-679.
2. Yan X, Guan C, Mueller A, Iezzi B, He M, Liang H, et al. Outcomes and projected impact on vision restoration of the China million cataract surgeries program. Ophthalmic Epidemiol. 2013; 20 (5): 294300 .

3. Hashemi H, Mohammadi SF, Z-Mehrjardi H, Majdi M, Ashrafi E, Mehravaran S, et al. The role of demographic characteristics in the outcomes of cataract surgery and gender roles in the uptake of postoperative eye care: a hospital-based study. Ophthalmic Epidemiol. 2012; 19 (4): 242-248.

4. Matta S, Park J, Subash P, Shantha G, Khanna RC, Rao GN. Cataract surgery visual outcomes and associated risk factors in secondary level eye care centers of L V Prasad Eye Institute, India. PLoS One, 2016; 11 (1): e0144853.

5. Chaudhary C, Bahadhur H, Gupta N. Study of cystoid macular edema by optical coherent tomography following uneventful cataract surgery. Int Ophthalmol. 2015; 35 (5): 685-691.

6. Haripriya A, Chang DF, Reena M, Shekhar M. Complication rates of phacoemulsification and manual small-incision cataract surgery at Aravind Eye Hospital. J Cataract Refract Surg. 2012; 38 (8): 1360-1369.

7. World Health Organization. Programme for the Prevention of Deafness. Global initiative for the elimination of avoidable blindness. Available at: http://www.who.int/iris/handle/10665/63748 (2000). Accessed January 2, 2018.

8. Conrad-Hengerer I, Hengerer FH, Joachim SC, Schultz T, Dick HB. Femtosecond laser-assisted cataract surgery: How far have we come? J Cataract Refract Surg. 2015; 41 (9): 1833-1838.

9. Dick HB, Conrad-Hengerer I, Schultz T. Intraindividual capsular bag shrinkage comparing standard and laser-assisted cataract surgery. J Refract Surg. 2014; 30 (4): 228-233.

10. Gaskin GL, Pershing S, Cole TS, Shah NH. Predictive Modeling of Risk Factors and Complications of Cataract Surgery. Eur J Ophthalmol. 2016; 26 (4): 328-337.

11. Lundström M, Goh PP, Henry Y, Salowi MA, Barry P, Manning S, et al. The Changing Pattern of Cataract Surgery Indications: A 5-year Study of 2 Cataract Surgery Databases. Ophthalmology, 2015; 122 (1): 3138.

12. Ti SE, Yang YN, Lang SS, Chee SP. A 5-year audit of cataract surgery outcomes after posterior capsule rupture and risk factors affecting visual acuity. Am J Ophthalmol. 2014; 157 (1): 180-185.

13. Venkatesh $\mathbf{R}$, Muralikrishnan $\mathbf{R}$, Balent LC, Prakash SK, Prajna NV. Outcomes of high volume cataract surgeries in developing countries. $\mathrm{Br} J$ Ophthalmol. 2005; 89 (9): 1079-1083. 
14. González N, Quintana JM, Bilbao A, Vidal S, de Larrea NF, Díaz V, et al. Factors Affecting Cataract Surgery Complications and Their Effect on the Postoperative Outcome. Can J Ophthalmol. 2014; 49 (1): 72-79.

15. Hashemi H, Mohammadpour M, Jabbarvand M, Nezamdoost Z, Ghadimi H. Incidence of and risk factors for vitreous loss in resident-performed phacoemulsification surgery. J Cataract Refract Surg. 2013; 39 (9): 1377-1382.

16. Asencio MA, Huertas M, Carranza R, Tenias JM, Celis J, Gonzalez-Del Valle F. A case-control study of post-operative endophthalmitis diagnosed at a Spanish hospital over a 13-year-period. Epidemiol Infect. 2015; 143 (1): 178-183.

17. Haripriya A, Chang DF, Reena M, Shekhar $M$. Complication rates of phacoemulsification and manual small-incision cataract surgery at Aravind Eye Hospital. J Cataract Refract Surg. 2012; 38 (8): 1360-1369.
18. Erie J. Rising cataract surgery rates: Demand and Supply. Ophthalmology, 2014; 121 (1): 2-4.

19. Klein BE, Howard KP, Lee KE, Klein R. Changing Incidence of Lens Extraction over 20 Years: The Beaver Dam Eye Study. Ophthalmology, 2014; 121 (1): 5-9.

20. Lewallen S, Courtright P. Gender and use of cataract surgical services in developing countries. Bull World Health Organ, 2002; 80 (4): 300-303.

\section{Authors' Designation \& Contribution}

Muhammad Ali Haider; Assistant Professor: Study Design, Data Collection, Write manuscript.

Uzma Sattar; Optometrist: Result, Data Analysis, final review.

Muhammad Amjad; Consultant Ophthalmologist: editing, Manuscript review.

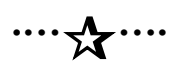

